\title{
HEALTHCARE WASTE MANAGEMENT IN THE PREFECTURES OF AETOLOAKARNANIA AND THE ISLAND OF LESBOS, GREECE
}

\author{
KAMITSOU H.A. ${ }^{1}$ \\ KALAVROUZIOTIS I.K. ${ }^{2}$ \\ PAPADAKI M. ${ }^{1}$
}

University of Patras, Department of Environment and Natural Resources

G. Seferi 2, Agrinio, Greece

Hellenic Open University, Faculty of Science and Technology Tsamadou 13-15 \& Saint Andrea, 262 22, Patras, Greece
Received: 22/01/2015

Accepted: 04/05/2015

Available online: 07/05/2015 *to whom all correspondence should be addressed: e-mail: ikalabro@eap.gr

\begin{abstract}
Proper Hospital healthcare Waste Management (HCWM) is imperative for ensuring public health and environmental protection. In this context, three Prefectural hospitals of Mytilene, Agrinio, and Messolonghi, were studied with respect to planning and management of infectious wastes, cost, training of the white Staff involved, security measures to be taken, and also knowledge related to the implementation of the existing National and European Community, legislation. It was found that the existing legislative procedures were broadly applied. However deviations were reported and it was recognized that serious difficulties in the implementation of the legislation throughout the process i.e. from the phase of separation throughout the processing phase did exist. These deviations frequently originated from conflicts in the directions given by the legislation Joint [Governmental Gazette B1537/85-2012]. In order to achieve better implementation of HCWM, recommendations are proposed here.
\end{abstract}

Keywords: Waste Hospitals, health and environmental protection

\section{Introduction}

Depending on their origin, hospital healthcare wastes are divided into three main groups (Bakopoulou et al., 2006; Komilis et al., 2012):

- Household type (kitchens, restaurants, cafes, plaster casts, office waste, etc). This category of solid waste can be easily mixed with the solid waste from residential areas and be subjected to the same methods of treatment.

- Specific healthcare waste such as those containing toxic and/or radioactive substances must follow the previewed management route along with other hazardous waste of this type, which usually originate from industry.

- Infectious (virulent or potentially virulent) healthcare waste, deserve special attention, because they pose a risk to public health.

According to the most recent legislation, i.e. JMD 146163 / 2012 "Measures and Terms on the Waste Management from Sanitary Units" [Governmental Gazette B1537/8-5-2012], which constitutes the basis of Greek legislation of Management of Hospital healthcare Wastes, the classification of Waste from Sanitary Units is as follows:

* Urban Solid Waste (USW), which simulate domestic waste.

* Hazardous Waste from Sanitary Units (HWSU) which consist of: 
$>$ Waste Purely Contagious (HWPC), are those wastes that have come into contact with blood, human secretions or other body fluids and they can infect and cause germ diseases.

$>$ Mixed Hazardous Waste (MHW). This category includes wastes from pathologoanatomic laboratories or departments where chemotherapy is used, and includes tissues, organs, body parts, animals aimed for experiments, waste containing mercury or asbestos or other heavy metals, cytotoxic - cytostatics - chemotherapy and other medications.

$>$ Other Hazardous Waste. This category includes chemicals that consist of hazardous substances.

- Specific waste streams (SWS). Radioactive, batteries, containers with pressurized gases, etc.

The different types of wastes require different methods of process and disposal.

Approximately $75-90 \%$ of Healthcare Waste $(\mathrm{HCW})$ are considered non-hazardous (that is similar to household waste), while the remaining $10-25 \%$ are considered dangerous, with the possibility of causing contamination in case they come in contact with a healthy person or if the person is exposed to them. (HealthCareWaste, 2001-2013a; EEDSA, 2006). Investigations showed that waste production depends on many factors including the established methods of healthcare waste management, the type of healthcare facilities, the number and kind of medical specialties, the proportion of reusable items used in health care and the proportion of patients per therapeutic care day (Prüss et al., 1999). Improper collection and separation of HCW results in increased cost of treatment since infectious or toxic waste can be also mixed with urban-type waste. This is primarily due to the lack of awareness and training of workers regarding the proper collection and separation of such waste. The above factors affect and render very difficult the evaluation of HCW approximate quantities (Tsakona et al., 2007). Direct contact with the Hazardous Healthcare Waste due to poor management, or indirect contact through the food chain in which the hazardous substances enter via soil or ground water for example, is dangerous. People working in waste treatment facilities or other areas where workers manually handle raw waste, are at greater risk of infection from healthcare waste (Salkin, 2004; Johannessen et al., 2000). Possible hazards originate from contact with sharp objects, blood or blood products and other body fluids, cultures and stocks of infectious agents from laboratories, pathological waste and animal waste (Salkin, 2004). A simple system of separation of such healthcare waste at the source in three separate containers (for sharp, infectious and household type wastes) before they are subjected to further downstream treatment, is a practical and cost-effective method of separation, which when appropriately applied, drastically reduces the main risks (HealthCareWaste, 2001-2013b). In 1992 United Nations conference, Agenda 21 was adopted, where the following recommendations for healthcare waste management were proposed: 1) Prevent and minimize waste production, 2) Reuse and recycle waste, 3) Treatment of waste with safe methods, 4) Deposition of them in landfills residues. The first step towards the implementation of the aforementioned Agenda is to conduct research on the site of waste production, focusing on the kind and the quantities of different types of waste. This is an imperative requirement before any specific plans aiming at the reduction of the waste generation and waste reuse and recycling are developed (Prüss et al., 1999). According to $\mathrm{WHO}$, the route that healthcare waste follow can be separated into 8 steps (HealthCareWaste, 2001-2013c), the first one being minimization of their generation with appropriate planning, before they are produced. Such a division can be proven useful for the more efficient planning of the management of hazardous waste. Collection of HCW should be organised in bags or other type of containers in the most suitable form for the treatment method to be followed; for example: the HCW for sterilization should be placed in yellow bags, for incineration in red bags and sharps in a punctureresistant, autoclave, hard, plastic containers. The temporary storage of $\mathrm{HCW}$, in SU, should be done in specially designed spaces, of adequate capacity and under conditions where there is no risk of deterioration of waste (Governmental Gazette B1537/8-5-2012). The transport of healthcare waste is made either by the sanitary unit or by a specialized company, which has been contracted by the hospital. Drivers and operators must be appropriately trained and should be familiar with the type of waste and the risks posed by them (Prüss et al., 1999). The most prevalent method of treatment for most dangerous $\mathrm{HCW}$ is incineration. It is a process used for waste that cannot be recycled or reused or disposed of in suitable disposal facilities. Some of the treatment options, reduce infectious risks of HCW efficiently, but 
at the same time, cause other risks to health and environment (such as toxic emissions or other harmful effects). The method of chemical disinfection is used in the SU to kill microorganisms in the medical equipment, floors and walls, and now is also used for the treatment of HCW (Prüss et al., 1999). A research conducted for the Special Environmental Inspectorate (SEI), for the management of hazardous HCW in Greece in 2011 concluded that in most cases there was no proper management of HCW (personal communication, SEI, 2011). Moreover, most of the SU actions were totally lacking the appropriate licenses. According to a biannual survey conducted in Kuwait, the quantities of dangerous HCW produced in the country, represented $31 \%$ of the total solid hazardous waste. Moreover, no recycling program was carried out, while infectious waste was processed with incineration (Alhumoud et al., 2007). Following research conducted in Kenya, the majority of the physicians had only attended seminars, or had been informed within the SU about HCW. In addition to that, most of the Staff was not using proper protective equipment or in some cases, such protective means did not even exist. Moreover, the majority of personnel (95\%), had experienced some kind of accident, which in the majority were needlestick injuries (Njagi et al., 2012). According to a survey conducted by the World Health Organization, it was found that in Albania, only one third of SU make separation of HCW. There was production of sharp waste which could have been totally avoided and it was discarded along with USW, endangering public health and scavengers. This was due to the absence of national strategy, training and lack of appropriate equipment (HealthCareWaste, 2006a). In Georgia, there was no proper storage of HCW neither properly separation of HCW. This resulted in mixing of HCW with the USW and their disposal without any treatment. Finally, we should note that in both countries there was no proper training of employees, or any appropriate financial resources to do so (HealthCareWaste, 2006b). According to WHO, an average gross estimate of the distribution of expenses of a HCWM system, accounts for an approximate $30-40 \%$ for containerization and storage; $10-20 \%$ for transport; $5-10 \%$ for cleaning and disinfection and $40-50 \%$ for treatment (HealthCareWaste, 2001-2013d). Taking specific measures during the management of healthcare waste, the costs mentioned above can be reduced. In order to achieve the best possible protection of Staff, and all those who come in direct contact with healthcare waste, some security measures must be taken. Moreover regular training, primarily of workers who come in direct contact with them and of the remaining hospital Staff, is required (Prüss et al., 1999).

In this work the current status of three hospital units in two different regions of Greece (mainland and islands) is recorded. The study is associated with the issues raised above, and more specifically with the collection and treatment of dangerous infectious HCW. The hospitals of the Prefecture of Aetoloakarnania (Agrinio, Messolonghi) and the hospital of the isle of Lesbos (Mytilene) were selected and are shown in this study. Aetoloacarnania is a poor prefecture in the mainland of Greece, which is also lacking train or motorway type of connection with any of the metropolitan cities of Greece, while Lesbos, is a remote, but the third largest Greek island (approx 90,000 permanent inhabitants on an area of 1,636 $\mathrm{km}^{2}$ ). Although it is a relatively isolated island it is also a favorite tourist destination; thus it displays a large seasonal fluctuation of the number of people which have to be treated throughout the year.

Medical wastes include anatomical, pathological, infectious, hazardous and other non-hazardous healthcare waste materials (Mousiopoulos et al., 2002; Johannessen et al., 2000). In order to protect the environment, public health and quality of life, it is necessary and imperative to design a suitable and rational management system for hospital wastes (NOHARM; Voulgaridou, 2009). Thus, the overall aim of the present study was to evaluate healthcare waste management planning at those hospitals in Greece in order to assess the extent to which the existing methods of management conform with the norms and additional measures that can be suggested so as to ensure that the public health is not jeopartized. Additionally, the study employing the aforementioned three selected hospitals, which were in distinctly different locations, could also highlight the effects that the location of a hospital can have on the process of the handling and treatment of such waste. 


\section{Methodology}

An appropriate questionnaire was prepared and distributed to selected people in three hospitals: The General Hospital of Agrinio in Aetoloacarnania, the General Hospital of Messolonghi, also in Aetoloacarnania and the General Hospital of Mytilene called "Vostanio" in the island of Lesvos. All but the General Hospital of Messolonghi have an Intensive Care Unit. The survey was conducted in the period 2012-2013.

The questionnaire was addressed to the managers responsible for healthcare waste management of the hospital and to selected white Staff members from each unit. More specifically, the questionnaires were addressed to the following categories of white Staff: Public health supervisors, nurse in charge of surveillance of infections, health visitor, clinical supervisor, supervisor of surgery and head of technical services. All questionnaires were completed through a personal interview conducted by the first author of the present work. The survey was conducted through personal interviews in order to gain better, well justified by facts answers. The interviews were held in many categories of the Staff in order to see whether they were up to date on the relevant to their duties issues of hospital healthcare waste management and whether they implemented them appropriately. In this manner, the results reported here are more reliable as they were validated by facts, examples provided by the interviers and cross examination of given answers. Additionally they information collected was more detailed than it would have been if the questionairies were anonymous without any personal interview sessions. The questionnaire included 24 questions, covering the following topics: General descriptive information (5 questions), production of infectious waste (2 questions), waste management (8 questions), waste management costs (1 question) personnel training on the management of waste ( 3 questions and 1 sub-question) workers safety related directly to the management ( 2 questions) and management legislation (2 questions). Overall 31 questionnaires were asked to be answered by the white Staff of all three hospitals.

\section{Results and discussion}

All but one (overall 30) questionnaires were answered by the white Staff of all three hospitals. A questionnaire addressed to a clinical supervisor was not answered. Several problems were encountered in the process of the collection of the required via the questionnaires data. Initially, there were difficulties and delays in obtaining the necessary authorization to carry out the investigation. Then, the Staff was reluctant to speak while being interviewed. They had serious concerns as to what they were supposed to say and as to whether certain statements they would make could be perceived as exposing weaknesses of their units or as lack of loyalty to their colleagues who were working very hard under extremely difficult conditions. Overcoming reservations of the interviewed person to express their views freely was a very difficult task, but it is believed that eventually all gave their honest opinion and trustworthy data. This would not be possible if the questionnaires were anonymous and without any personal interview sessions and interaction for two reasons; first, the Personnel would try to finish them quickly without giving any extensive thinking to each question; second, because except for the managers responsible for the waste management of the hospital, the remaining white Staff did not know exactly what the survey was about; their requests for additional explanations were well accommodated via the interview. Moreover, the lack of time of the Staff to deal with the questionnaire, and their occasional inability to respond with precise amounts / numbers, made the collection of data more difficult of a job. The collected data were analyzed and the correlation of the answers given to each question are discussed in more detail in the following sections. According to the analysis of the questionnaires:

\subsection{Number of beds}

The average number of beds in hospitals of the survey is 179. Essentially all three hospitals are small. The General Hospital of Mytilene "Vostanio" being the largest of the three, has the greatest number of beds (252), followed by the General hospital of Agrinio with 160 beds, and the General Hospital of Messolonghi with 120 beds as it is shown in Chart 1. 


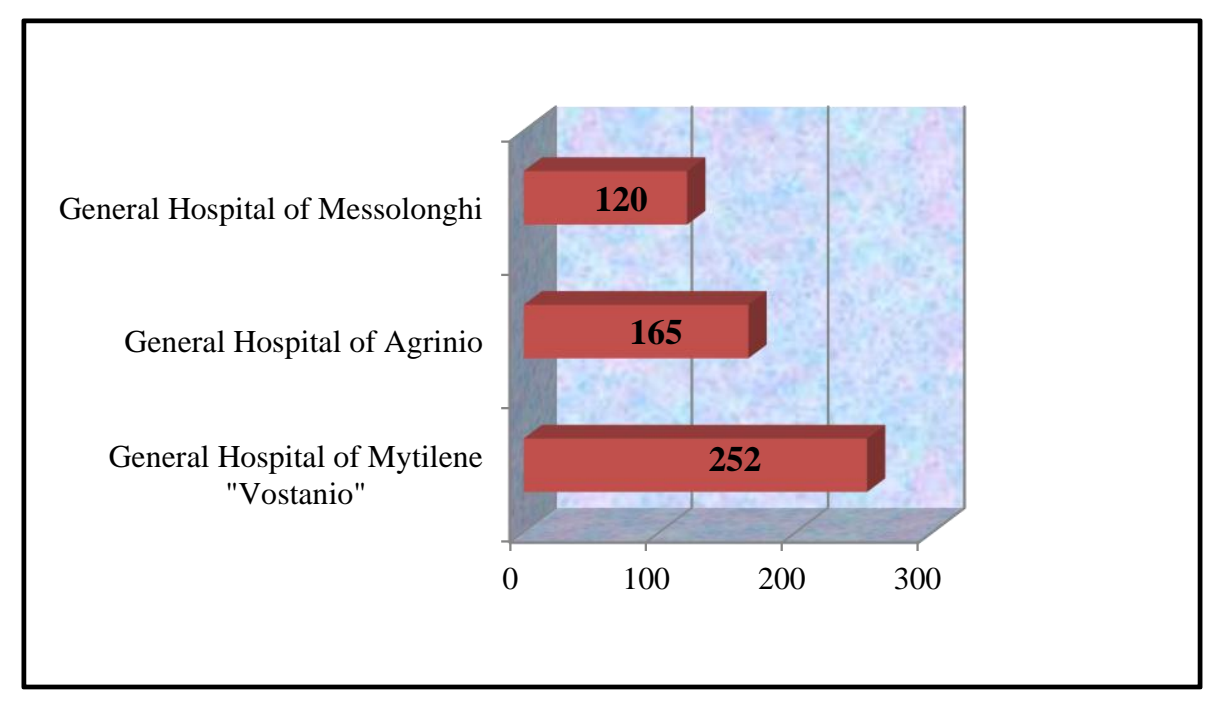

Figure 1. Number of beds per sanitary unit

\subsection{Quantities of infectious waste produced}

The quantity of infectious medical waste produced varies from $0.945 \mathrm{~kg} \mathrm{~d}^{-1}$ per bed (General Hospital of Agrinio) to $0.27 \mathrm{~kg} \mathrm{~d}^{-1}$ per bed (General Hospital of Mytilene "Vostanio") for HWPC, with an average of $0.645 \mathrm{~kg} \mathrm{~d}^{-1}$ per bed. Furthermore, the quantity of MHW varies from $0.085 \mathrm{~kg} \mathrm{~d}^{-1}$ per bed (General Hospital of Agrinio) to $0.001 \mathrm{~kg} \mathrm{~d}^{-1}$ per bed (General Hospital of Messolonghi) with an average of $0.055 \mathrm{~kg} \mathrm{~d}^{-1}$ per bed (Komilis and Katsafaros,2011; Eker and Bilgili,2011).

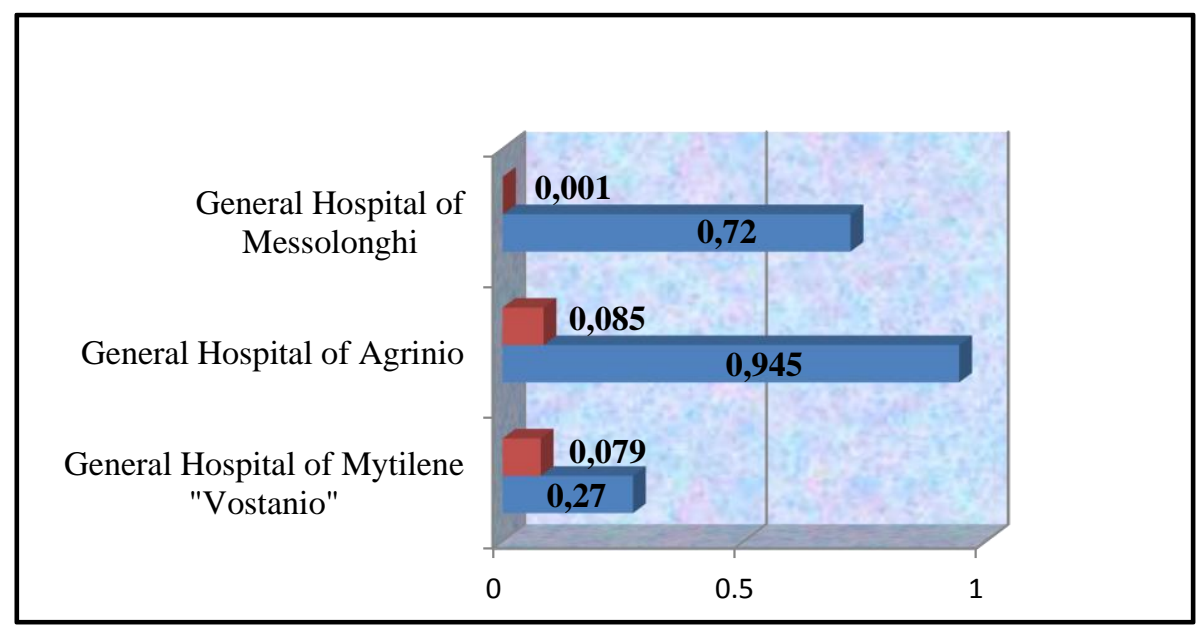

Figure 2. Production of infectious healthcare waste per sanitary unit.

Produced quantity ( $\mathrm{kg} \mathrm{day}^{-1}$ per bed). Red bars indicate MHW and blue bars HWPC

It is remarkable that although the General Hospital of Mytilene "Vostanio" has more beds than the other two hospitals produces less quantity of infectious waste with a strong divergence in the case of HWPC, although one would expect for it to produce a larger quantity of infectious HCW (Healthcare Waste). This could be, due to the implementation of a more effective separation of the HWPC in this hospital compared to that of the other two SUs. Of course, it is impossible to know exactly the produced quantity of each category of waste, as these depend on both the quality of separation and the waste control implemented in each hospital unit and it resulted that the answers to the questions of questionnaire could not address this issue effectively. It was therefore concluded that most likely, the General Hospital of Mytilene "Vostanio" has larger quantities of USW compared to the other two units, as it had less quantity of HWPC as it is shown in Chart 2. Two of the hospitals, the General Hospital of Mytilene and the General Hospital 
of Agrinio, were studied in a period at which there was an increase in their waste. The General Hospital of Mytilene was tested in the summer season, during which the number of inhabitants in the island are over double due to tourism. The General Hospital of Agrinio was tested during a period that Intensive Care Unit was in use, and an increase in the number of patients, due to the financial crisis which had become quite pronounced in the area. In contrast, in the General Hospital of Messolonghi where there was no intensive care unit, where was observed a reduction due to the depopulation of the region.

\subsection{The management process:}

\subsubsection{Segregation:}

In all hospitals, medical waste were separated in fractions similar to household waste in USW and also in HWSU close to the site of production, as defined by JMD 146163/2012 "Measures and Terms on the Waste Management from Sanitary Units"(Governmental Gazette B1537/8-5-2012). At the General Hospital of Mytilene "Vostanio" special attention was paid to the other hazardous waste. However, the respondents often remarked that due to momentum, occasional errors in waste separation did occur. Sometimes they occurred by mistake during the separation process; in other occasions, the lack of awareness and understanding of various management issues related to the environmental protection and health was to be blamed for. As such, in all cases where the separation waste was not correct, hazardous waste contaminated the USW rendering them hazardous too, thus, unnecessarily increasing the quantity of the final HWSU. However, the latter cause of errors was not reported as a key problem and it was thought that it could be easily resolved through periodical training and by appropriately scheduled updating of training of the Staff involved. On the other hand, they firmly highlighted that the continued reduction of the hospital Staff, which put excessive pressure on the remaining employees, cannot guarantee elimination of the former cause of mistakes in separation.

\subsubsection{Collection}

The medical Urban Solid Waste (USW), that are similar to the household waste, were collected in black plastic bags in all hospitals studied. According to the JMD (Governmental Gazette B1537/8-5-2012), Hazardous Waste Purely Contagious (HWPC) must be placed in containers of yellow or red color depending on the final processing. So, the HWPC which are going to be sterilized, should be placed in yellow bags and then in yellow boxes, while those HWPC intended for incineration, must be placed in red bags, and then in red boxes. On the other hand, sharp objects should be collected in high-density, nonperforated - autoclave, hard, plastic containers (other than PVC), and closed by a safety lid. Furthermore, the boxes must be provided with a receiving hole, and must be resistant to penetration and leakage. Then, depending on the treatment that is to follow, they should be placed into a receptor (hospital box type) with a corresponding color. However, many times due to lack of financial resources in all hospital units, there was a lack of the necessary packaging material and thus collection of waste was carried out in the most suitable available type of packaging, which in many cases did not fulfill the requirements set by JMD (Governmental Gazette B1537/8-5-2012). This resulted in complications in the process of treatment, due to the imprecision in the color. The subsequent treatment to be followed was difficult since the same color of packaging was used for both methods of treatment.

\subsubsection{Treatment}

The treatment method followed by all hospitals, for HWPC, is sterilization, which takes place in the town of Volos, in mainland Greece by the Joint Stock company "Sterilization S.A.". In addition, the method of treatment of the Mixed Hazardous Waste (MHW) at all three hospitals was incineration. This was carried out in ESDKNA in Athens, the capital of Greece. In all cases, a contractor had been assigned to collect and transport the MHW from each hospital to the incineration facility at a precise frequency and time specified in detail in the contract.

\subsubsection{Labelling}

According to the JMD [Governmental Gazette B1537/8-5-2012] all packaging waste should be labeled with the basic information about their content and production details. Specifically, it must have an embedded 
waterproof label written by permanent ink, and bear the international symbol and the corresponding labeling of infectious and / or hazardous waste (according to the UN class in which the waste has been classified). Furthermore the term "hazardous waste", must be clearly displayed, as well as the class and the UN number for their risk. Finally, date of production and packaging of the waste, the precise location of production (chamber / section / lab), quantity and destination of the waste must be indicated. Unfortunately, in all of the hospitals studied, the labeling of the contained material was frequently insufficient for the receptors. More specifically:

- None of the hospital units mentioned the existence of embedded waterproof labels by indelible ink.

- $\quad$ All three hospitals indicated clearly the term "Hazardous Waste".

- Only the General Hospital of Agrinio mentioned the indication of class and UN number as to their risk. It did not mention however, some of the required additional information.

- Although in all three units wastes were being labeled, in none of them labeling was fully consistent as specifically is defined by the JMD (Governmental Gazette B1537/8-5-2012).

\subsubsection{Inter-hospital transport}

For the transportation of infectious waste from the collection points to the temporary storage area in the three hospitals, closed type specific wheeled metal-bins were being used, as specifically is defined by the law.

\subsubsection{Storage}

The temporary storage of HWPC and MHW samples was conducted in all three hospitals in accordance with what is defined by JMD (Governmental Gazette B1537/8-5-2012). So, the storage took place in specially designed cold storage spaces of sufficient capacity under conditions that did not allow the alteration of the waste. Specifically:

- At the General Hospital of Mytilene "Vostanio", being in an island, and due to the inaccessibility of the incineration facilities, the residence time of waste lasted for thirty (30) days at $0{ }^{\circ} \mathrm{C}$.

- At the General Hospital of Agrinio, the residence time of waste was approximately five days at temperatures not exceeding $0{ }^{\circ} \mathrm{C}$.

- Finally, at the General Hospital of Messolonghi, residence time of the waste was approximately 5-7 days at $0{ }^{\circ} \mathrm{C}$.

\subsubsection{Minimisation}

The recycling of the HCW programs were $100 \%$ applied in all three hospitals. More specifically, all three hospitals performed recycling of paper and battery in cooperation with the municipality to which they belong. Furthermore, the General Hospital of Mytilene "Vostanio" carried out recycling of plastic, of lubricating oils, of printer inks (toners) and of all types of light bulbs. The General Hospital of Messolonghi performed recycling of lamps and household type waste (such as plastic, etc.) in blue bins.

However, it must be pointed out that for reasons which are beyond the scope of this work, or the beyond the responsibility of the hospitals to control the process, it was observed that there were irregularities, and the recycling was either not carried out correctly or although it was carried out correctly, the materials collected for recycling ended-up in landfills.

\subsection{Cost of management}

The management cost of HWPC per kilogram per year, varies from $1.2 € \mathrm{~kg}-1$ (General Hospital Messolonghi) up to $2.7 € \mathrm{~kg}-1$ (General Hospital of Mytilene). The management cost of MHW per kilogram per year, ranges from $1.7 € \mathrm{~kg}-1$ (General Hospital of Agrinio and General Hospital of Messolonghi) up to $3 €$ kg-1 (General Hospital of Mytilene). The high divergences between the General Hospital of Mytilene and General Hospital of Agrinio and Messolonghi, are due to the increased transportation costs of HCW by ship, because of the remote location of the unit (island). The above results are depicted in Chart 3 . The 
contract for the management cost of HCW is conducted annually. In case that there is a problem of, either irregular payments from the unit, or improper waste management by the company, the contract is terminated followed by negotiations, for a new agreement.

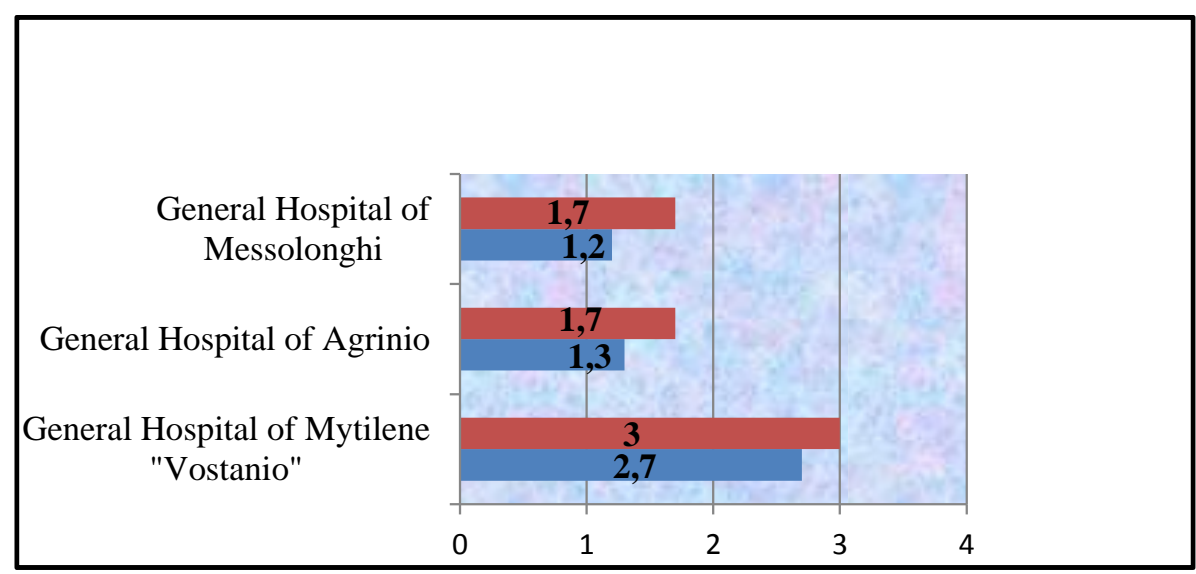

Figure 3. Cost of management of healthcare waste per sanitary unit $\left(€ \mathrm{~kg}^{-1}\right)$. Red bars indicate MHW and blue bars HWPC

Table 1. Cost of management with the method of healthcare waste incineration (Ecocycle, 2011; Prüss et al., 1999)

\begin{tabular}{lcc}
\hline Country & Method of management & Cost of management $(€ / \mathrm{kg})$ \\
\hline Greece & Incineration & 2.13 \\
\hline Switzerland & Incineration & 0.286 \\
\hline N.America & Incineration & 0.069 \\
\hline
\end{tabular}

Table 1 shows the cost of management for different locations. In Table 1 it is shown that significant differences do exist between the cost of management in Greece (considering the average of the studied areas), with a cost which is higher by $1.844 € \mathrm{~kg}-1$ for Greece as compared to Switzerland and $2.061 € \mathrm{~kg}$ 1 as compared to North America. This is certainly affected by the cost of fuel which is much lower for North America, while in the case of Greece it is very expensive especially after the increased taxation that has been imposed in fuels in Greece since recession started. However, it is also very likely that the cost of treatment is also affected by the types of incinerator used and the quantities of the HCW to be treated. The location of incinerator unit, which is available only in one place in Greece and the lack of competition which could arise should more incinerator units were available could result in reduced costs. Additionally the construction of more incinerators in appropriate locations could effectively reduce the cost of treatment if a reduction of the transport distance is achieved. Moreover, factors like recycle of reuse of medical components or a better separation of $\mathrm{HCW}$ by the Staff, which leads to a reduction in processing costs (although the latter requires higher labour costs), may also have a contributing effect.

\subsection{Training of personnel}

\subsubsection{Number and position of the persons involved in the management}

As it was found from the personal interviews, none of the nursing units had a single person being exclusively in charge of the management of healthcare waste. Our understanding was that the waste management member of Staff had broader administrative duties, with HCWM being one of them. At regular intervals, of a duration of six months or so, the Management Committee of waste assigned the top waste-management responsibility to a member of Staff who had to undertake the management of the healthcare waste together with their usual duties. This member of Staff could be having an extensive range of normal responsibilities, such as being the Director of the Hospital, or could be in a much lower rank of the administration, such as being the supervisor of a section. However, the shift of this responsibility from person to person could cause to the assigned employee the impression that HCWM is 
not so important. This is believed to inevitably result in an ineffective control throughout the course of the implementation of the management system.

\subsubsection{Clearly defined responsibilities}

All the nursing units had clearly defined responsibilities. This was a positive element which helps to avoid inconsistencies and shortcomings during the management of medical waste.

\subsubsection{Types of training}

In all hospital units a program for the training of the hospitals Staff was performed about the hazards of waste, the posed risks and the recommended way of waste management. In the two of the three hospital units (General Hospital of Mytilene and Agrinio), Staff training was about education on collection, separation and transport of HCW. On the other hand, in the case of the General Hospital of Messolonghi, training of personnel was through informative lectures and postings in the clinics with the types of waste. In all units, the training was carried out by the responsible for HCWM.

\subsubsection{Frequency of training}

Staff training took place twice a year at the General Hospital of Mytilene, once a year at the General Hospital of Messolonghi, while at the General Hospital of Agrinio the training was continuous and with readjustments. In all units, additional training was also conducted in relation to the health and safety of workers.

\subsection{Personal Safety Protection of employees}

\subsubsection{Protective clothing}

Protective clothing was always used in the General Hospital of Mytilene. On the contrary, because of inadequate financial resources in the main, the necessary protective clothing was not made available to the employees of the General Hospital of Agrinio and Mesolonghi, who apparently did not regularly use protective clothing. Thus, the safety and health of workers was put at risk.

\subsubsection{Infections during the management}

No cases of infection of the Staff, originating from the waste had been reported in the General Hospital of Agrinio. In the other two hospitals, very rare incidents had been reported and registered. The usual causes of infection were due to injuries from sharp objects such as needles, which were improperly separated.

\subsubsection{Measures to prevent future infections}

The strategic approach of all three hospitals in order to prevent infections originating from HCWF, was to continue training of the personnel in combination with preventive measures, such as required vaccination, aiming at preventing and eliminating such or similar events in the future.

\subsection{Legislation}

All hospital units have internal regulations, on the basis of which they perform the management of HCW. In addition, all the operators of HCWM in all HCWF, know the existence of legislative regulations. Two of the three hospitals (General Hospital of Mytiline and General Hospital of Agrinio), were well informed of the recently put in effect JMD 146163 "Measures and Terms on the Waste Management from Sanitary Units"[Governmental Gazette B1537/8-5-2012]. The General Hospital of Messolonghi had only conformed with the older legislation (Governmental Gazette B 1419/1-10-2003).

\section{Conclusions}

It was found that despite the general compliance with the rules during the application, there were frequent deviations from the directions defined by JMD [Governmental Gazette B1537/8-5-2012], primarily originating due to limited finances. This is an important issue, which all hospitals face presently 
in Greece, where funding has been reduced, while more and more people need to use their services, as private healthcare becomes prohibited for the population's limited financial resources. This is a serious side-effect of recession. Additional problems were found in all phases of the process, from the separation phase until the phase of processing.

To avoid the problems, it is proposed:

- Frequent and effective white Staff training

- Assignment of a white Staff member with the required background, whose sole responsibility will be the HCWM

- Increased financial support to the units from the State, with earmarked funds for HCWM

- Frequent inspections of units for regulation compliance of their HCWM and

- Implementation of penalties for irregularities.

In addition, the best way of waste collection, is to separate the waste materials into the appropriate groups, i.e. surgical, pathological etc at the source, and to record the exact quantities of each fraction and its relative weight contributing in the total amount of waste.

Moreover, each unit should devise a methodology so as to be always in line with the most recent regulations regarding HCW methods of management and also how to keep their Staff's education always up-to-date.

Finally, the construction of local incineration units could be examined.

\author{
Abbreviations \\ HCW - Healthcare Waste \\ HCWF - Commander of Healthcare Waste Facilities \\ HCWM - Healthcare Waste Management \\ HWPC - Hazardous Waste Purely Contagious \\ HWSU - Hazardous Waste from Sanitary Units \\ JMD - Joint Ministerial Decision \\ MHW - Mixed Hazardous Waste \\ SU - Sanitary Units \\ SWS - Specific Waste streams \\ USW - Urban Solid Waste
}

\title{
Acknowledgements
}

The authors wish to thank the managers of the General Hospital of Mytilene, Agrinio and Messolonghi for their excellent cooperation. Also we express our gratitude to persons in charge of the Hospital Waste Management, and generally to all those who helped and contributed to the completion of the present work.

\section{References}

Alhumoud J.M., Alhumoud H.M. (2007), An analysis of trends related to hospital solid wastes management in Kuwait, Management of Environmental Quality, 18, $502-513$.

Bakopoulou S., Kougolos A. and Arabosis K. (2006), Regional Hospital Waste Management Planning As a mean of determining the required investments: The case of Thessaly Region. 2nd international conference of the Hellenic Solid Waste Management Association, e - proceedings, February 3 - 4, Athens, Greece.

Ecocycle (2011), http://www.ecocycle.org/files/pdfs/WTE_wrong_for_environment_economy_community_by_Eco-Cycle.pdf, (accessed June 2013).

EEDSA (2006), http://www.eedsa.gr/Contents.aspx?Catld=125, in Greek, (accessed February 2013).

Eker H.H. and Bilgili M.S. (2011), Statistical analysis of waste generation in healthcare services: a case study, Waste Manag. Res., 29, 791-796. 
Governmental Gazette B 1537/8-5-2012, Joint Ministerial Decision 146163/2012 "Measures and Terms on the Waste Management from Sanitary Units", (in Greek). Available at:

http://www.elinyae.gr/el/lib file upload/1537b 12.1337252766296.pdf .

Governmental Gazette B 1419/1-10-2003 Joint Ministerial Decision 37591/2031/2003, “Measures and Terms for the Management of Medical Waste from Sanitary Units" (in Greek). Available at: http://www.ggb.gr/LinkClick.aspx?fileticket=a_5EI6KQYMw\%3D\&tabid=84\&language=en-US.

HealthCareWaste (2001-2013a), http://www.healthcarewaste.org/basics/categories, (accessed February 2013).

HealthCareWaste (2001-2013b), http://www.healthcarewaste.org/basics/risk-reduction/, (accessed February 2013).

HealthCareWaste (2001-2013c), http://www.healthcarewaste.org/basics/waste-steps/, (accessed February 2013).

HealthCareWaste (2001-2013d), http://www.healthcarewaste.org/resources/costing-calculations, (accessed February 2013).

HealthCareWaste (2006a), http://www.healthcarewaste.org/resources/case-studies/albania/, (accessed February 2013).

HealthCareWaste (2006b), http://www.healthcarewaste.org/resources/case-studies/georgia/, (accessed February 2013).

Johannessen L.M., Dijkman M., Bartone C., Hanrahan D., Boyer M.G. and Candace C. (2000), "Health Care Waste Management Guidance Note", HNP, Available at: http://www.bvsde.ops-oms.org/bvsacd/cd49/carewaste.pdf, (accessed February 2013).

Komilis D. and Katsafaros N. (2011). Statistical predictors of hazardous medical waste generation rates in a 40-bed general hospital, Global NEST Journal, 13, 170-175.

Komilis D. Fouki A. and Papadopoulos D. (2012), Hazardous medical waste generation rates of different categories of health-care facilities, Waste Management, 32, 1434-1441.

Mousiopoulos N.and Karagiannidis A. (2002), "Notes on lesson of Waste Management", Thessaloniki, pp 4, (in Greek) Available at: http://aix.meng.auth.gr/lhtee/education/swm1.pdf, (accessed February 2013).

Njagi N.A., Oloo M.A., Kithinji J. and Kithinji J.M. (2012), Knowledge, Attitude and Practice of Health-Care Waste Management and Associated Health Risks in the Two Teaching and Referral Hospitals in Kenya, J. Community Health, 37, 1172-1177.

NOHARM, http://www.noharm.org/europe/issues/waste/, (accessed February 2013).

Prüss A., Giroult E. and Rushbrook P. (1999), "Safe management of wastes from health-care activities", World Health Organization, Geneva.

Salkin I.F. (2004), "Review of Health Impacts from Microbiological Hazards in Health-Care Wastes", Department of Blood Safety and Clinical Technology and Department of Protection of the Human Environment World Health Organization, Geneva. Available at:

http://www.who.int/water_sanitation_health/medicalwaste/en/microbhazards0306.pdf.

SE.I (2011), "Research for the Management of Hazardous Waste Hospital Questionnaire 2010", Summary Results.

Tsakona M., Anagnostopoulou E. and Gidarakos E. (2007), Hospital waste management and toxicity evaluation: A case study, Waste Manag., 27(7), 912-20.

Voulgaridou P. (2009), "The Solid Waste Management in lasmos of Prefecture of Rodopi", Harokopio University of Greece, Department of Home Economics and Ecology, pp 17, in Greek. Available at: http://estia.hua.gr:8080/dspace/handle/123456789/923. 